\title{
Spectral, NLO, Fluorescence, and Biological Activity of Knoevenagel Condensate of $\beta$-Diketone Ligands and Their Metal(II) Complexes
}

\author{
S. Sumathi, ${ }^{1}$ C. Anitha, ${ }^{1}$ P. Tharmaraj, ${ }^{1}$ and C. D. Sheela ${ }^{2}$ \\ ${ }^{1}$ Department of Chemistry, Thiagarajar College, Madurai 625 009, India \\ ${ }^{2}$ Department of Chemistry, The American College, Madurai 625 002, India
}

Correspondence should be addressed to P. Tharmaraj, sheelatharmaraj@gmail.com

Received 21 November 2011; Revised 18 December 2011; Accepted 18 December 2011

Academic Editor: Wolfgang Linert

Copyright (c) 2011 S. Sumathi et al. This is an open access article distributed under the Creative Commons Attribution License, which permits unrestricted use, distribution, and reproduction in any medium, provided the original work is properly cited.

\begin{abstract}
Transition metal complexes of various acetylacetone-based ligands of the type $\mathrm{ML}$ (where $\mathrm{M}=\mathrm{Cu}(\mathrm{II}), \mathrm{Ni}(\mathrm{II}), \mathrm{Co}(\mathrm{II}) ; \mathrm{L}=3$ (aryl)-pentane-2,4-dione) have been synthesized. The structural features have been derived from their elemental analysis, magnetic susceptibility, molar conductance, IR, UV-Vis, $\mathrm{H}^{1} \mathrm{NMR}$, mass and ESR spectral studies. Conductivity measurements reveal that all the complexes are nonelectrolytic in nature. Spectroscopic and other analytical data of the complexes suggest square planar geometry for copper(II), cobalt(II), and nickel(II) complexes of 3-(3-phenylallylidene)pentane-2,4-dione and octahedral geometry for other metal(II) complexes. The redox behaviors of the copper(II) complexes have been studied by cyclic voltammetry. The free ligands and their metal complexes have been screened for their in vitro biological activities against bacteria and fungus. The metal(II) complexes are found to possess increased activities compared to those of the free ligands. All synthesized compounds may serve as potential photoactive materials as indicated from their characteristic fluorescence properties. The second harmonic generation (SHG) efficiency of the ligands was found to have considerable effect compared to that of urea and KDP.
\end{abstract}

\section{Introduction}

$\beta$-diketone and its metal complexes have been widely used in diverse areas because of their unique structural features, chemical functionalities, and toughness for light and heat as electroluminescence materials [1]. $\beta$-diketone derivatives possess a broad spectrum of biological effects such as antiinflammatory and antimicrobial activity effects [2-6].

Nonlinear optics has received considerable attention due to its variety of applications in optoelectronic and photonic devices. A wide variety of materials have been investigated for NLO, among which both organic and inorganic materials are attractive because of their optical and electronic properties which can be tailored by structural modification [7-11]. There is a need to design and develop the nonlinear optical materials to meet the present demand due to their widespread applications such as high-speed information processing, optical communications, and optical data storage $[12,13]$. With an aim to develop novel optical materials, in recent years, some NLO response compounds $[14,15]$ were designed and prepared by our group. In an attempt to increase the NLO response of $\beta$-diketone, here different aromatic aldehydes were introduced in active methylene group.

In this connection, our aim is to synthesize the ligands which have NLO property and pharmacological activities. This paper reports the spectroscopic characteristics of 3(aryl)-pentane-2,4-dione-chelated metal(II) complexes prepared by the condensation of acetylacetone with different substituted aromatic aldehydes, and NLO, fluorescence, and biological descriptions are presented.

\section{Experimental}

All chemicals and solvents were purchased from commercial sources. Acetylacetone, benzaldehyde, and cinnamaldehyde were Merck India, SD fine products and used as supplied. Solvents were double distilled and stored in molecular sieves (4 $\AA$ ) before use. For voltammetric experiments, tetrabutylammonium perchlorate (TBAP) (Sigma) was used 
as supporting electrolyte. NMR measurement was made on a BRUKER $300 \mathrm{MHz}$ spectrometer. The UV-Vis spectra were recorded on a THERMO SPECTRONIC 6 HEXIOS $\alpha$, and fluorescence spectra were performed on ELICO SL174 spectrofluorometer using DMSO as solvent. EI mass was recorded by GEOL-GC MATE-2 mass spectrometer. The IR spectra were carried out by using SHIMADZU FTIR 8400 spectrophotometer. ESR spectra of the copper(II) complexes were obtained at 300 and $77 \mathrm{~K}$ using DPPH (diphenylpicrylhydrazide) as the g-marker. Magnetic susceptibility of the complexes was measured on a Sherwood Magnetic susceptibility balance Mk1. Cyclic voltammetric studies for $\mathrm{Cu}$ (II) complexes in DMSO were taken on a $\mathrm{CH}$ Instruments (USA). Molar conductance of the complexes was measured in DMSO at room temperature using Systronic Conductivity Bridge 304. All the complexes were screened for biological activity through well diffusion method.

2.1. Synthesis of 3-(Aryl)-pentane-2,4-dione (L1, L2). The nonenolisable diketone was prepared by employing the modified procedure reported earlier [16]. Acetylacetone (3 g, $1 \mathrm{mmol}$ ) was mixed with substituted aromatic aldehydes ( $1 \mathrm{mmol}$ ) (benzaldehyde $(3.1 \mathrm{~g}, 1 \mathrm{mmol})$ and cinnamaldehyde (3.9 g, $1 \mathrm{mmol})$, resp., for L1 and L2), and piperidine $\left(0.05 \mathrm{~cm}^{3}\right)$ in ethanol $(50 \mathrm{~mL})$, and the reaction mixture was stirred thoroughly for a period of $6 \mathrm{~h}$ with occasional cooling. Gradually a yellow precipitate was separated in small amounts. The reaction mixture was set aside to evaporate to dryness, and the residual solid was washed with an excess of petroleum ether to remove any unreacted reagents. Washing was repeated two to three times, and the compound was recrystallized from ethanol to give a yellow solid Knoevenagel condensate (see Supplementary Figures 3 and 4 in Supplementary Material available online at doi: 10.1155/2011/154326).

L1-Yield: $80 \%$, m.p: $132^{\circ} \mathrm{C}\left[{ }^{1} \mathrm{H}\right.$ NMR, 7.11-7.40 $\delta(\mathrm{m}$, aromatic proton). $8.229 \delta(\mathrm{s},-\mathrm{C}=\mathrm{CH}-\mathrm{Ar})$ [17], $2.09 \delta(\mathrm{s}$, methyl proton) $[18] ;{ }^{13} \mathrm{C} \mathrm{NMR}, 8$ peaks corresponding to the carbon atom; Mass spectra, $[\mathrm{M}]^{+}$at $\left.188 \mathrm{~m} / \mathrm{e}\right]$.

L2-Yield: $70 \%$, m.p: $126^{\circ} \mathrm{C}\left[{ }^{1} \mathrm{H}\right.$ NMR, $7.23-7.90 \delta$ (m, aromatic proton). $8.251 \delta(\mathrm{s},-\mathrm{C}=\mathrm{CH}-\mathrm{Ar}), 2.69 \delta(\mathrm{s}$, methyl proton), $6.68 \delta(\mathrm{t},-\mathrm{CH}=\mathrm{CH}) ;{ }^{13} \mathrm{C}$ NMR, 10 peaks corresponding to the carbon atom; Mass spectra, $[\mathrm{M}]^{+}$at $214 \mathrm{~m} / \mathrm{e}]$.

2.2. Synthesis of Metal(II) Complexes. The metal complexes were prepared by the addition of hot solution of the appropriate metal chloride $(1 \mathrm{mmol})$ in ethanol $(25 \mathrm{~mL})$ to the hot solution of the 3-(aryl)-pentane-2,4-dione ( $1 \mathrm{mmol})$ in the same solvent $(25 \mathrm{~mL})$. The resulting mixture was stirred under reflux for one hour whereupon the complex precipitated. They were collected by filtration, washed thoroughly with ethanol, and dried in vacuum.

2.3. Nonlinear Optical Properties (NLO) of 3-(Aryl)-pentane2,4-dione (L1, L2). The SHG conversion efficiency of 3(aryl)-pentane-2,4-dione (L1, L2) was determined by modified version of powder technique developed by Kurtz and
Perry [19]. The ligands were ground into powder and packed between two transparent glass slides. An Nd:YAG laser beam of wavelength $1064 \mathrm{~nm}$ was made to fall normally on the sample cell. The transmitted fundamental wave absorbed by a $\mathrm{CuSO}_{4}$ solution removes the incident $1064 \mathrm{~nm}$ light, and Filter BG-38 also removes any residual $1064 \mathrm{~nm}$ light. Interference filter band width is $4 \mathrm{~nm}$ and of central wavelength $532 \mathrm{~nm}$. The green light is finally detected by the photomultiplier tube and displayed on the oscilloscope. The second harmonic signal was detected by a photomultiplier tube and displayed on a storage oscilloscope. The efficiency of the sample was compared with that of microcrystalline powder of KDP and urea. The input energy used in this particular setup is $2.2 \mathrm{~mJ} /$ pulse.

2.4. Biological Activity. Antimicrobial activity of the compounds was tested in vitro by the well diffusion method [20] against the bacteria Pseudomonas aeruginosa, Escherichia coli, and Staphylococcus aureus using agar nutrient as the medium. Also the antifungal activity against the fungus Candida albicans cultured on potato dextrose using agar as medium was tested. About $0.5 \mathrm{~mL}$ spore suspension of each investigated organism was added to a sterile Petri dish and left to solidify, and the well was made in each plate with the help of a cork-borer $(6 \mathrm{~mm})$. The stock solution $\left(10^{-3} \mathrm{~mol} / \mathrm{L}\right)$ was prepared by dissolving the compounds in DMSO. The plates were inoculated with microorganisms and filled with the test solution for $24 \mathrm{~h}$ for bacteria and $48 \mathrm{~h}$ for fungus at $37^{\circ} \mathrm{C}$. The activity was measured in terms of zone of inhibition against bacteria and fungus appearing around the well.

\section{Result and Discussion}

The analytical data and physical properties of the 3-(aryl)pentane-2,4-dione (L1 and L2) and metal(II) complexes are presented in Table 1. The molar conductance of the complexes implies that all the complexes are not electrolytes. The analytical data of the complexes are in good agreement with the general formula $\left[\mathrm{M}(\mathrm{L} 1) \mathrm{X} \cdot 2 \mathrm{H}_{2} \mathrm{O}\right]$, where $\mathrm{M}=\mathrm{Cu}(\mathrm{II})$, $\mathrm{Ni}(\mathrm{II}), \mathrm{Co}(\mathrm{II}) ; \mathrm{X}=2 \mathrm{Cl}^{-}$except copper(II), cobalt(II), and nickel(II) complexes of 3-(3-phenylallylidene)pentane-2,4dione, which is of $[\mathrm{M}(\mathrm{L} 2) \mathrm{X}]$ type. The magnetic moment of the complexes is consistent with octahedral and square planar geometry around central metal ion for $\left[\mathrm{M}(\mathrm{L} 1) \mathrm{X} \cdot 2 \mathrm{H}_{2} \mathrm{O}\right]$ and $[\mathrm{M}(\mathrm{L} 2) \mathrm{X}]$ types, respectively (Figures 1 and 2 ).

3.1. Mass Spectra. In the mass spectrum of 3-(aryl)-pentane2,4-dione and metal(II) complexes, the molecular ion peaks for the ligands $\mathbf{L} 1$ and $\mathbf{L} 2$ were observed at 188 and $214 \mathrm{~m} / \mathrm{z}$, whereas the $\mathrm{M}+/ \mathrm{M}+2$ peak for nickel(II) (L1c) was observed at 353, 355 corresponds to $\left[\mathrm{MLCl}_{2} \cdot 2 \mathrm{H}_{2} \mathrm{O}\right]$. Similarly, cobalt(II) complex of 3-(3-phenylallyidene)pentane2,4-dione (L2b) exhibits the molecular ion and $\mathbf{M}+2$ peak at $342,344 \mathrm{~m} / \mathrm{z}$ corresponds to $\left[\mathrm{MLCl}_{2}\right]$. Peak at 355 and $344 \mathrm{~m} / \mathrm{z}$ in L1c and L2b, respectively, corresponds to isotopic peak which also confirms the presence of chlorine ion in the complexes (Supplementary Figures 5 and 6). 
TABLE 1: Elemental analysis, molar conductance, and magnetic susceptibility data of ligands L1 and L2 and their metal(II) complexes.

\begin{tabular}{|c|c|c|c|c|c|c|}
\hline \multirow{2}{*}{ Compound } & \multirow{2}{*}{$\begin{array}{l}\mathrm{m} \cdot \mathrm{p} \\
\left({ }^{\circ} \mathrm{C}\right)\end{array}$} & \multicolumn{3}{|c|}{ Calculated (Found), \% } & \multirow{2}{*}{$\begin{array}{c}\Lambda_{\mathrm{M}} \\
\left(\mathrm{S} \mathrm{cm}^{2} \mathrm{M}^{-1}\right)\end{array}$} & \multirow{2}{*}{$\begin{array}{c}\mu_{\text {eff }} \\
(\mathrm{BM})\end{array}$} \\
\hline & & M & C & $\mathrm{H}$ & & \\
\hline L1 & 132 & - & $76.5(76.4)$ & $6.38(6.36)$ & - & - \\
\hline$\left[\mathrm{CuL1Cl}{ }_{2} \cdot 2 \mathrm{H}_{2} \mathrm{O}\right] \mathbf{L} \mathbf{1 a}$ & $160-162$ & $17.6(17.4)$ & $40.2(40.0)$ & $3.35(3.31)$ & 10 & 1.95 \\
\hline$\left[\mathrm{CoL} 1 \mathrm{Cl}_{2} \cdot 2 \mathrm{H}_{2} \mathrm{O}\right] \mathbf{L 1} \mathbf{b}$ & $154-157$ & $16.5(16.4)$ & $40.7(40.2)$ & $3.39(3.35)$ & 9 & 4.71 \\
\hline$\left[\mathrm{NiL} \mathrm{Cl}_{2} \cdot 2 \mathrm{H}_{2} \mathrm{O}\right] \mathbf{L 1 c}$ & $171-172$ & $16.4(16.2)$ & $40.5(40.0)$ & $3.38(3.35)$ & 15 & 3.21 \\
\hline L2 & 126 & - & $78.5(78.3)$ & $6.54(6.50)$ & - & - \\
\hline$\left[\mathrm{CuL}_{2} \mathrm{Cl}_{2}\right] \mathbf{L} \mathbf{2 a}$ & $156-158$ & $16.4(16.1)$ & $43.7(43.5)$ & $4.68(4.66)$ & 18 & 1.79 \\
\hline$\left[\mathrm{CoL}_{2} \mathrm{Cl}_{2}\right] \mathbf{L} \mathbf{2 b}$ & $149-151$ & $17.1(16.8)$ & $48.9(48.6)$ & $4.07(4.05)$ & 14 & 1.85 \\
\hline$\left[\mathrm{NiL}_{2} \mathrm{Cl}_{2}\right] \mathbf{L} \mathbf{2 c}$ & $163-165$ & $17.0(16.7)$ & $48.8(48.4)$ & $4.05(4.03)$ & 12 & 一 \\
\hline
\end{tabular}<smiles></smiles>

$$
\mathrm{R}=\mathrm{C}_{6} \mathrm{H}_{5} ; \mathrm{M}=\mathrm{Cu}(\mathrm{II}), \mathrm{Co}(\mathrm{II}), \mathrm{Ni}(\mathrm{II})
$$

FIGURE 1: Synthesis of metal(II) complexes (L1a, L1b, L1c).

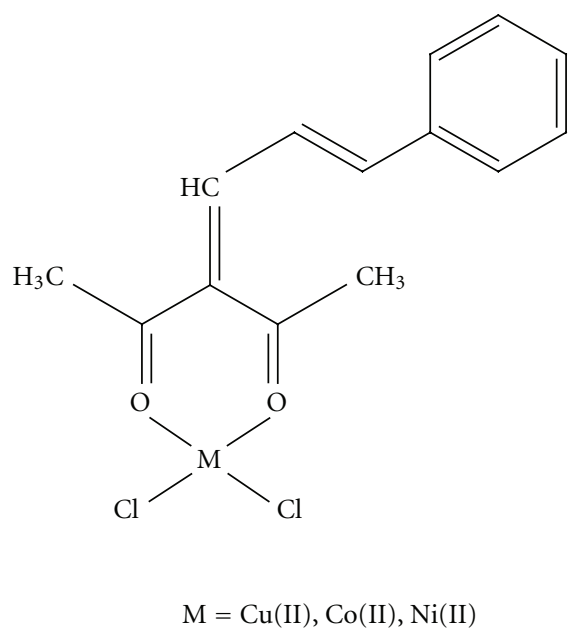

Figure 2: The proposed structure of metal(II) complexes (L2a, L2b, and L2c).

3.2. IR Spectra. Acetylacetone and its derivative are capable of exhibiting keto-enol tautomerism, but the Knoevenagel condensate of $\beta$-diketone with aldehyde produces a nonenolisable product [21]. The IR spectral data of the ligands (L1 and L2) and their metal(II) complexes are listed in Table 2. The spectral bands for ligands (L1 and L2) appears in the range of $1695,1699 \mathrm{~cm}^{-1}$ and $1600,1629 \mathrm{~cm}^{-1}$ are assigned to the stretching vibrations of $\nu(\mathrm{C}=\mathrm{O})$ and $\nu(\mathrm{C}=\mathrm{C})$ $[22,23]$ respectively. The shifting of the same bands to lower frequency in all the metal(II) complexes implies the coordination of carbonyl group to the central metal ion. The band at around $3400 \mathrm{~cm}^{-1}$ for the complexes ascertains the existence of coordinated water in all the complexes except copper(II), cobalt(II), and nickel(II) of L2. The new 
TABLE 2: IR spectral data $\left(\mathrm{cm}^{-1}\right)$ of ligands $\mathbf{L} 1$ and $\mathbf{L} 2$ and their metal(II) complexes.

\begin{tabular}{lccc}
\hline Compound & $v(\mathrm{C}=\mathrm{O})$ & $\nu(\mathrm{C}=\mathrm{C})$ & $\nu(\mathrm{OH})$ of $\mathrm{H}_{2} \mathrm{O}$ \\
\hline L1 & 1695 & 1600 & - \\
L1a & 1676 & 1548 & 3448 \\
L1b & 1629 & 1540 & 3427 \\
L1c & 1683 & 1563 & 3419 \\
L2 & 1699 & 1629 & - \\
L2a & 1651 & 1597 & - \\
L2b & 1687 & 1614 & - \\
L2c & 1685 & 1620 & - \\
\hline
\end{tabular}

TABLE 3: Electronic spectral data $\left(\mathrm{cm}^{-1}\right)(\varepsilon)$ of metal(II) complexes.

\begin{tabular}{|c|c|c|c|}
\hline Complexes & Frequency $(\varepsilon)$ & Assignment & Geometry \\
\hline \multirow{3}{*}{ L1a } & $23148(3015)$ & INCT & \multirow{3}{*}{ Distorted octahedral } \\
\hline & $21097(2131)$ & INCT & \\
\hline & $9460(856)$ & ${ }^{2} \mathrm{E}_{\mathrm{g}} \rightarrow{ }^{2} \mathrm{~T}_{2 \mathrm{~g}}$ & \\
\hline \multirow{3}{*}{ L1b } & $9541(350)$ & ${ }^{4} \mathrm{~T}_{1 \mathrm{~g}}(\mathrm{~F}) \rightarrow{ }^{4} \mathrm{~T}_{2 \mathrm{~g}}(\mathrm{~F})$ & \multirow{3}{*}{ Distorted octahedral } \\
\hline & $16420(760)$ & ${ }^{4} \mathrm{~T}_{1 \mathrm{~g}} \rightarrow{ }^{4} \mathrm{~A}_{2 \mathrm{~g}}$ & \\
\hline & 19047 (1289) & ${ }^{4} \mathrm{~T}_{\mathrm{lg}}(\mathrm{F}) \rightarrow{ }^{4} \mathrm{~T}_{\mathrm{lg}}(\mathrm{P})$ & \\
\hline \multirow{3}{*}{ L1c } & $10582(410)$ & ${ }^{3} \mathrm{~A}_{2 \mathrm{~g}} \rightarrow{ }^{3} \mathrm{~T}_{2 \mathrm{~g}}$ & \multirow{3}{*}{ Distorted octahedral } \\
\hline & $14471(997)$ & ${ }^{3} \mathrm{~A}_{2 \mathrm{~g}} \rightarrow{ }^{3} \mathrm{~T}_{1 \mathrm{~g}}(\mathrm{~F})$ & \\
\hline & $25038(1425)$ & ${ }^{3} \mathrm{~A}_{2 \mathrm{~g}} \rightarrow{ }^{3} \mathrm{~T}_{1 \mathrm{~g}}(\mathrm{P})$ & \\
\hline \multirow{2}{*}{$\mathrm{L} 2 \mathrm{a}$} & $23529(1895)$ & INCT & \multirow{2}{*}{ Square planar } \\
\hline & $18867(530)$ & ${ }^{2} \mathrm{~B}_{1 \mathrm{~g}} \rightarrow{ }^{2} \mathrm{~A}_{1 \mathrm{~g}}$ & \\
\hline \multirow{2}{*}{ L2b } & $16474(285)$ & ${ }^{2} \mathrm{~B}_{2} \rightarrow{ }^{2} \mathrm{E}_{\mathrm{g}}$ & \multirow{2}{*}{ Square planar } \\
\hline & $21852(355)$ & ${ }^{4} \mathrm{~A}_{1 \mathrm{~g}} \rightarrow{ }^{4} \mathrm{~B}_{1 \mathrm{~g}}$ & \\
\hline \multirow{2}{*}{ L2c } & $15337(543)$ & ${ }^{1} \mathrm{~A}_{1 \mathrm{~g}} \rightarrow{ }^{1} \mathrm{~B}_{1 \mathrm{~g}}$ & \multirow{2}{*}{ Square planar } \\
\hline & $21582(1564)$ & ${ }^{1} \mathrm{~A}_{1 \mathrm{~g}} \rightarrow{ }^{1} \mathrm{~A}_{2 \mathrm{~g}}$ & \\
\hline
\end{tabular}

band that appeared in the $520-532 \mathrm{~cm}^{-1}$ region in the case of complexes is assigned to $v(\mathrm{M}-\mathrm{O}$ ) [24] (Supplementary Figures 7 and 8).

3.3. Electronic Spectra. The electronic absorption spectral data $\left(\mathrm{cm}^{-1}\right)$ of the metal(II) complexes are given in Table 3. Copper(II) complex (L1a) displays three absorption bands at $23148 \mathrm{~cm}^{-1}, 21097 \mathrm{~cm}^{-1}$ and $9460 \mathrm{~cm}^{-1}$, which are assigned as an intraligand charge transfer (INCT) band [25], ligandto-metal charge transfer band, and ${ }^{2} \mathrm{E}_{\mathrm{g}} \rightarrow{ }^{2} \mathrm{~T}_{2 \mathrm{~g}}$ transitions,

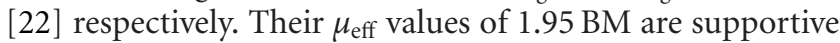
of octahedral geometry around $\mathrm{Cu}$ (II) [26]. $\mathrm{Co}$ (II) complex (L1b) exhibits three $\mathrm{d}-\mathrm{d}$ bands at $9541 \mathrm{~cm}^{-1}, 16420 \mathrm{~cm}^{-1}$ and $19047 \mathrm{~cm}^{-1}$ assigned to ${ }^{4} \mathrm{~T}_{1 \mathrm{~g}}(\mathrm{~F}) \rightarrow{ }^{4} \mathrm{~T}_{2 \mathrm{~g}}(\mathrm{~F}),{ }^{4} \mathrm{~T}_{1 \mathrm{~g}} \rightarrow$ ${ }^{4} \mathrm{~A}_{2 \mathrm{~g}}$, and ${ }^{4} \mathrm{~T}_{1 \mathrm{~g}}(\mathrm{~F}) \rightarrow{ }^{4} \mathrm{~T}_{1 \mathrm{~g}}(\mathrm{P})$ transitions [27], respectively, and the magnetic moments for the cobalt(II) complexes in the $4.71 \mathrm{BM}$ range are supportive of octahedral geometry [28]. Similarly, Ni(II) complex (L1c) shows bands at $10582 \mathrm{~cm}^{-1}, 14471 \mathrm{~cm}^{-1}$ and $25038 \mathrm{~cm}^{-1}$ due to ${ }^{3} \mathrm{~A}_{2 \mathrm{~g}} \rightarrow$ ${ }^{3} \mathrm{~T}_{2 \mathrm{~g}},{ }^{3} \mathrm{~A}_{2 \mathrm{~g}} \rightarrow{ }^{3} \mathrm{~T}_{1 \mathrm{~g}}(\mathrm{~F})$, and ${ }^{3} \mathrm{~A}_{2 \mathrm{~g}} \rightarrow{ }^{3} \mathrm{~T}_{1 \mathrm{~g}}(\mathrm{P})$ transitions [29], respectively. The magnetic moment values of the above $\mathrm{Ni}$ (II) complexes fall in the range of $3.21 \mathrm{BM}$, which is in the normal range observed for octahedral $\mathrm{Ni}$ (II) complexes $\left(\mu_{\text {eff }}=2.9-3.3 \mathrm{BM}\right)[26,30]$. This indicates that the complex of $\mathrm{Ni}(\mathrm{II})$ is six-coordinate and probably octahedral geometry [31].

The electronic spectrum of the present 3-(3-phenylallylidene)pentane-2,4-dione copper(II) complex (L2a) showed absorption band at $18867 \mathrm{~cm}^{-1}(530 \mathrm{~nm})$ assigned to ${ }^{2} \mathrm{~B}_{1 \mathrm{~g}} \rightarrow$ ${ }^{2} \mathrm{~A}_{\mathrm{lg}}$ transition, which corresponds to a square planar geometry around $\mathrm{Cu}(\mathrm{II})$ ion [32]. The absence of absorption below $10000 \mathrm{~cm}^{-1}$ excludes the possibility of tetrahedral geometry for the complexes. Additional band at $23529 \mathrm{~cm}^{-1}$ $(425 \mathrm{~nm})$ attributed to INCT may also in the spectra of square planar complexes [33]. The magnetic moment of the copper(II) complex is $1.79 \mathrm{BM}$ and is also supportive of square planar geometry.

In the electronic spectrum of cobalt(II) (L2b) complex the bands at $16474 \mathrm{~cm}^{-1}$ and $21852 \mathrm{~cm}^{-1}$ are assigned to ${ }^{2} \mathrm{~B}_{2} \rightarrow{ }^{2} \mathrm{E}_{\mathrm{g}}$ and ${ }^{4} \mathrm{~A}_{\mathrm{lg}} \rightarrow{ }^{4} \mathrm{~B}_{1 \mathrm{~g}}$ transitions [34], respectively, characteristic of square planar geometry, and the same is further evidenced by its magnetic moment value $1.85 \mathrm{BM}$ [35]. Similarly, in the UV spectrum of nickel(II) (L2c) complex the bands at $15337 \mathrm{~cm}^{-1}$ and $21582 \mathrm{~cm}^{-1}$ arising from ${ }^{1} \mathrm{~A}_{1 \mathrm{~g}} \rightarrow{ }^{1} \mathrm{~B}_{1 \mathrm{~g}}$, and ${ }^{1} \mathrm{~A}_{1 \mathrm{~g}} \rightarrow{ }^{1} \mathrm{~A}_{2 \mathrm{~g}}$ transitions, respectively [36], and its magnetic moment value also confirm square planar geometry [37]. 
TABLE 4: Redox potential for copper(II) complexes.

\begin{tabular}{lccc}
\hline Complexes & $E_{\mathrm{pc}}(\mathrm{V})$ & $E_{\mathrm{pa}}(\mathrm{V})$ & $\Delta E_{\mathrm{p}}(\mathrm{V})$ \\
\hline L1a & 0.062 & 0.780 & 0.712 \\
L2a & 0.102 & 0.766 & 0.765 \\
\hline
\end{tabular}

TABLE 5: The spin Hamiltonian parameters of copper(II) complexes.

\begin{tabular}{lccccccccc}
\hline Copper(II) complex & $A_{\text {iso }}$ & $\begin{array}{c}g_{\text {iso }} \\
\left(10^{-4} \mathrm{~cm}^{-1}\right)\end{array}$ & $g_{\|}$ & $g_{\perp}$ & $\begin{array}{c}A_{\|} \\
\left(10^{-4} \mathrm{~cm}^{-1}\right)\end{array}$ & $A_{\perp}$ & $\beta^{2}$ & $\begin{array}{r}g_{\|} / A_{\|} \\
(\mathrm{cm})\end{array}$ \\
\hline L1a & 121 & 2.29 & 2.28 & 2.06 & 122.3 & 116.2 & 0.34 & 2.98 & 186 \\
L2a & 180 & 2.32 & 2.29 & 2.15 & 122.1 & 115.9 & 0.33 & 2.70 & 176 \\
\hline
\end{tabular}

TABLE 6: Fluorescence parameters of ligands L1 and L2 and their metal(II) complexes in DMSO.

\begin{tabular}{lcc}
\hline \multirow{2}{*}{ Compound } & \multicolumn{2}{c}{ Emission maximum $(\mathrm{nm})$} \\
& $\mathbf{L 1}$ & $\mathbf{L 2}$ \\
\hline Ligand (L) & 498.5 & 379 \\
a-Cu(II) complex & $578,789,792$ & $595,684,784$ \\
b-Co(II) complex & $500,789,793$ & $486,785,793$ \\
c-Ni(II) complex & $677,787,795$ & $660,784,796$ \\
\hline
\end{tabular}

3.4. Electrochemical Behavior. The cyclic voltammograms (Table 4) of the copper(II) complexes recorded at room temperature using TBAP as the supporting electrolyte in the potential range 1.2 to $-1.2 \mathrm{~V}$ reveal that the peak current for the copper(II) complexes varies with the change of Knoevenagel condensate of 3-(aryl)-pentane-2,4-dione. The $E_{\mathrm{pa}}-E_{\mathrm{pc}}$ values are greater than $200 \mathrm{mV}$, which indicates that the reduction processes are irreversible [38] in nature and the ratio of anodic to cathodic peak currents corresponding to the chemical change occurs with the electron transfer as $\mathrm{Cu}(\mathrm{II}) \rightarrow \mathrm{Cu}(\mathrm{I}) \rightarrow \mathrm{Cu}(0)$.

3.5. EPR Spectra. The EPR spectra of copper(II) complexes were recorded in DMSO at 300 and $77 \mathrm{~K}$, and the spin Hamiltonian parameters of the complexes are listed in Table 5. The observed spectral parameters show that the $g_{\|}>g_{\perp}$ value is characteristic of an axially elongated octahedral geometry [37]. The covalent character of metalligand bond is inferred from the $g_{\text {iso }}$ values 2.29 and 2.32, and it also supports the fact that the unpaired electrons lie predominantly in the $d_{x^{2}-y^{2}}$ orbital. The $G$ values for the copper(II) (L1a) complex greater than 4 suggest that the local tetragonal axes are aligned parallel or slightly misaligned and are consistent with a $d_{x^{2}-y^{2}}$ ground state. For the other copper(II) complex (L2a) the $G$ value is less than 4 which indicates that the exchange coupling interaction is considerable and misalignment is appreciable. The calculated magnetic moment for the copper(II) complexes using the relation $\mu^{2}=3 / 4|g|^{2}$ is indicative of an unpaired electron. The $\alpha^{2}$ values suggest appreciable in-plane covalency in the molecule. The calculated value of $\left(g_{\|} / A_{\|}\right)$for the complexes is characteristic of distorted structure. The poor in-plane $\pi$ bonding in the complexes is reflected in their $\beta^{2}$ values. The molecular orbital coefficients $\alpha^{2}$ and $\beta^{2}$ were calculated using the Kivelson and Neiman formula [39] (Supplementary Figures 9 and 10):

$$
\begin{gathered}
\alpha_{\mathrm{Cu}}^{2}=\frac{A_{\|}}{p}+\left(g_{\|}-2.0023\right)+\frac{3}{7}\left(g_{\perp}-2.0023\right)+0.04, \\
\beta_{\mathrm{Cu}}^{2}=\frac{\left(g_{\|}-2.0023\right) E}{\left(-8 \lambda \alpha^{2}\right)} .
\end{gathered}
$$

3.6. Fluorescence Study. The fluorescent nature of 3-(aryl)pentane-2,4-dione (L1 and $\mathbf{L} 2$ ) and its metal(II) complexes are shown in Table 6. Ligands have been inferred from their emission bands around 379, $498 \mathrm{~nm}$. The metal(II) complexes of all the above ligands also exhibit three emission bands in the range of 486-796 nm. Significant differences in the positions of emissions maximum of 3-(aryl)-pentane2,4-dione and its complexes establish the complexation process [40]. All the complexes register broad emission bands indicating charge transfer nature of the transitions. Quenching of fluorescence of ligand by transition metal ions during complexation is a rather common phenomenon which is explained by processes such as redox activity and electronic energy transfer [41]. The free ligand shows an enhanced fluorescent intensity. This emission is neither MLCT nor LMCT in nature. It is known that lone pair of electron on oxygen and on carbonyl chromophore can quench the fluorescence of aromatic system through photoinduced electron transfer. This leads to draining out of these pairs of electrons onto the metal orbital via complex formation which causes a suppression of this fluorescence intensity [42] (Supplementary Figures 11 and 12).

3.7. NLO Property of 3-(Aryl)-pentane-2,4-dione. The SHG (second harmonic generation) efficiency of the two different acetylacetone-based Knoevenagel condensates is presented in Table 7. The SHG efficiency of the ligands L1 and L2 is better than that of the references (KDP and urea). The output energy for SHG is $4 \mathrm{mV}, 3 \mathrm{mV}, 13 \mathrm{mV}$, and $57 \mathrm{mV}$, respectively, for $\mathrm{L} 1, \mathrm{~L} 2, \mathrm{KDP}$, and urea. In general a molecule with delocalized $\pi$-electron system can have large nonlinear polarizabilities [43] and it has is generally understood that the molecular nonlinearity can be enhanced by systems with strong donor and acceptor groups [44]. From the analysis of electronic transitions and molecular orbital involved, ligand orbital can improve the NLO properties. 
TABLE 7: SHG parameters of different Knoevenagel condensates of 3-(aryl)-pentane-2,4-dione.

\begin{tabular}{lcr}
\hline Compound & SHG efficiency with respect to KDP & SHG efficiency with respect to urea \\
\hline L1 & 0.3 & 0.07 \\
L2 & 0.2 & 0.05 \\
\hline
\end{tabular}

TABle 8: Antimicrobial activity of the ligands $\mathbf{L} 1$ and $\mathbf{L} 2$ and their metal(II) complexes (zone of inhibition in $\mathrm{mm}^{* *}$; concentration in $\left.10^{-3} \mathrm{~mol} / \mathrm{L}\right)$.

\begin{tabular}{|c|c|c|c|c|c|c|c|c|}
\hline \multirow{2}{*}{ Compound } & \multicolumn{2}{|c|}{ P. aeruginosa } & \multicolumn{2}{|c|}{ S. aureus } & \multicolumn{2}{|c|}{ E. coli } & \multicolumn{2}{|c|}{ C. albicans } \\
\hline & L1 & L2 & L1 & $\mathrm{L} 2$ & L1 & L2 & L1 & L2 \\
\hline Ligand (L) & 8 & 10 & 8 & 6 & 8 & 5 & 8 & 8 \\
\hline a-Cu(II) complex & 14 & 16 & 15 & 10 & 9 & 9 & 11 & 11 \\
\hline b-Co(II) complex & 11 & 17 & 14 & 16 & 9 & 9 & 11 & 11 \\
\hline c-Ni(II) complex & 8 & 17 & 12 & 14 & $\mathrm{R}$ & 9 & 10 & 10 \\
\hline Standard & \multicolumn{2}{|c|}{18} & \multicolumn{2}{|c|}{18} & \multicolumn{2}{|c|}{18} & \multicolumn{2}{|c|}{12} \\
\hline
\end{tabular}

** Its value observed is within the error limits of \pm 1 . R: resistance.

3.8. Biological Activity. Zone-of-inhibition values of the investigated compounds against the bacteria and fungus are summarized in Table 8. Amikacin and ketoconazole have been used as reference compounds for antibacterial and antifungal activities, respectively. The observed values indicate that most of the complexes have higher activity than the free ligand. Such an increased activity of the complexes can be explained on the basis of chelation theory [45]. On chelation, polarity of the metal ion is reduced to a greater extent due the overlapping of the ligand orbital and partial sharing of the positive charge of the metal ion with donor groups. Moreover, delocalization of the $\pi$-electrons over the whole chelate ring is increased and lipophilicity of the complexes is enhanced. The increased lipophilicity enhances the penetration of the complexes into the lipid membranes and blocks the metal binding sites in the enzymes of microorganisms. These complexes also disturb the respiration process of the cell and thus block the synthesis of proteins, which restricts further growth of the organism. Investigation on similar type of complexes [46-48] reveals that metal complexes exhibit higher activity than their ligand. The compounds of our interest also exhibit higher activity than respective ligands, but in no case it is effective towards their standard drug.

\section{Conclusion}

A novel type of Knoevenagel condensate has been synthesized from acetylacetone, and various substituted aromatic aldehydes and their metal complexes for $\mathrm{M}: \mathrm{L}$ ratio $1: 1$ of $\mathrm{Cu}(\mathrm{II}), \mathrm{Co}(\mathrm{II})$, and $\mathrm{Ni}(\mathrm{II})$ were obtained. An octahedral structure has been proposed for all the metal(II) complexes except copper(II) (L2a), cobalt(II) (L2b), and nickel(II) (L2c) which showed square planar structure. Though some Knoevenagel condensed complexes have been found in the recent literature [47], these have been rarely seen as nonlinear optical materials in terms of second harmonic generation (SHG) efficiency. In our system the ligands L1 and L2 of Knoevenagel condensate are found to exhibit considerable nonlinear optical (NLO) property in comparison with urea and KDP. All the ligands and their metal(II) complexes are fluorescent in nature. Metal(II) complexes exhibited a considerable antimicrobial activity compared to the free ligands.

\section{Acknowledgments}

The authors thank the management of Thiagarajar College of Engineering, Madurai, and P. Tharmarai thanks the Defence Research and Development Organization (DRDO), New Delhi, for providing financial support and SAIF, IIT, Bombay, and SAIF, CDRI, Lucknow, for analytical facilities.

\section{References}

[1] G. Aromí, P. Gamez, and J. Reedijk, "Poly beta-diketones: prime ligands to generate supramolecular metalloclusters," Coordination Chemistry Reviews, vol. 252, no. 8-9, pp. 964989, 2008.

[2] T. Jeewoth, M. G. Bhowon, and H. L. K. Wah, "Synthesis, characterization and antibacterial properties of Schiff bases and Schiff base metal complexes derived from 2,3diaminopyridine," Transition Metal Chemistry, vol. 24, no. 4, pp. 445-448, 1999.

[3] P. S. Desai and K. R. Desai, "Synthesis and antibacterial activity of 2-(6'-chlorobenzothiazol-2'-ylamino)-4-N4-N1(n-butyl)sulphanilamido-6-(arylthioureido)-s-triazine derivatives," Journal of the Indian Chemical Society, vol. 70, pp. 177178, 1993.

[4] J. Lv, T. Liu, S. Cai, X. Wang, L. Liu, and Y. Wang, "Synthesis, structure and biological activity of cobalt(II) and copper(II) complexes of valine-derived schiff bases," Journal of Inorganic Biochemistry, vol. 100, no. 11, pp. 1888-1896, 2006.

[5] R. Del Campo, J. J. Criado, E. García et al., "Thiourea derivatives and their nickel(II) and platinum(II) complexes: antifungal activity," Journal of Inorganic Biochemistry, vol. 89, no. 1-2, pp. 74-82, 2002.

[6] S. Belaid, A. Landreau, S. Djebbar, O. Benali-Baitich, G. Bouet, and J. P. Bouchara, "Synthesis, characterization and 
antifungal activity of a series of manganese(II) and copper(II) complexes with ligands derived from reduced $\mathrm{N}, \mathrm{N}^{\prime}$ O-phenylenebis(salicylideneimine)," Journal of Inorganic Biochemistry, vol. 102, no. 1, pp. 63-69, 2008.

[7] Y. Liu, J. Zhou, X. Zhang et al., "Synthesis, characterization and optical limiting property of covalently oligothiophenefunctionalized graphene material," Carbon, vol. 47, no. 13, pp. 3113-3121, 2009.

[8] K. Sendhil, C. Vijayan, and M. P. Kothiyal, "Nonlinear optical properties of a porphyrin derivative incorporated in Nafion polymer," Optical Materials, vol. 27, no. 10, pp. 1606-1609, 2005.

[9] N. Tsuboya, R. Hamasaki, M. Ito, M. Mitsuishi, T. Miyashita, and Y. Yamamoto, "Nonlinear optical properties of novel fullerene-ferrocene hybrid molecules," Journal of Materials Chemistry, vol. 13, no. 3, pp. 511-513, 2003.

[10] M. N. Bhat and S. M. Dharmaprakash, "Effect of solvents on the growth morphology and physical characteristics of nonlinear optical $\gamma$-glycine crystals," Journal of Crystal Growth, vol. 242, no. 1-2, pp. 245-252, 2002.

[11] P. Nandakumar, C. Vijayan, and Y. V. G. S. Murti, "Optical absorption and photoluminescence studies on CdS quantum dots in Nafion," Journal of Applied Physics, vol. 91, no. 3, pp. 1509-1514, 2002.

[12] T. Verbiest, S. Houbrechts, M. Kauranen, K. Clays, and A. Persoons, "Second-order nonlinear optical materials: recent advances in chromophore design," Journal of Materials Chemistry, vol. 7, no. 11, pp. 2175-2189, 1997.

[13] Y. Zhang, H. Li, B. Xi, Y. Che, and J. Zheng, "Growth and characterization of l-histidine nitrate single crystal, a promising semiorganic NLO material," Materials Chemistry and Physics, vol. 108, no. 2-3, pp. 192-195, 2008.

[14] S. Sumathi, P. Tharmaraj, C. D. Sheela, and R. Ebenezer, "Synthesis, spectral, bioactivity, and NLO properties of chalcone metal complexes," Journal of Coordination Chemistry, vol. 64, no. 10, pp. 1707-1717, 2011.

[15] S. Sumathi, P. Tharmaraj, C. D. Sheela, R. Ebenezer, and P. Saravana Bhava, "Synthesis, characterization, NLO study, and antimicrobial activities of metal complexes derived from 3-(3-(2-hydroxyphenyl)-3-oxoprop-1-enyl)-4H- chromen-4one and sulfanilamide," Journal of Coordination Chemistry, vol. 64, no. 10, pp. 1673-1682, 2011.

[16] S. Srinivasan, P. Athappan, and G. Rajagopal, "Synthesis, spectral and redox properties of metal complexes of macrocyclic tetraaza chiral Schiff bases," Transition Metal Chemistry, vol. 26, no. 4-5, pp. 588-593, 2001.

[17] A. P. Zambre, V. M. Kulkarni, S. Padhye, S. K. Sandur, and B. B. Aggarwal, "Novel curcumin analogs targeting TNF-induced NF- $\kappa$ B activation and proliferation in human leukemic KBM5 cells," Bioorganic and Medicinal Chemistry, vol. 14, no. 21, pp. 7196-7204, 2006.

[18] N. Raman, R. Jeyamurugan, R. U. Rani, T. Baskaran, and L. Mitu, "Synthesis, characterization, DNA binding, oxidative damage of DNA strand scission, and antimicrobial activities of $\beta$-diketone condensed Schiff-base transition metal complexes," Journal of Coordination Chemistry, vol. 63, no. 9, pp. 1629-1644, 2010.

[19] S. K. Kurtz and T. T. Perry, "A powder technique for the evaluation of nonlinear optical materials," Journal of Applied Physics, vol. 39, no. 8, pp. 3798-3813, 1968.

[20] O. N. Irobi, M. Moo-Young, and W. A. Anderson, "Antimicrobial activity of Annatto (Bixa orellana) extract," International Journal of Pharmacognosy, vol. 34, no. 2, pp. 87-90, 1996.
[21] J. P. Annaraj, K. M. Ponvel, P. Athappan, and S. Srinivasan, "Synthesis, spectra and redox behavior of copper(II) complexes of curcumin diketimines as models for blue copper proteins," Transition Metal Chemistry, vol. 29, no. 7, pp. 722727, 2004.

[22] A. Kulkarni, P. G. Avaji, G. B. Bagihalli, S. A. Patil, and P. S. Badami, "Synthesis, spectral, electrochemical and biological studies of $\mathrm{Co}(\mathrm{II}), \mathrm{Ni}(\mathrm{II})$ and $\mathrm{Cu}(\mathrm{II})$ complexes with Schiff bases of 8-formyl-7-hydroxy-4-methyl coumarin," Journal of Coordination Chemistry, vol. 62, no. 3, pp. 481-492, 2009.

[23] A. Veeraraj, P. Sami, and N. Raman, "Copper(II) complex of 3cinnamalideneacetylacetone: synthesis and characterisation," Proceedings of the Indian Academy of Sciences: Chemical Sciences, vol. 112, no. 5, pp. 515-521, 2000.

[24] M. Kalanithi, D. Kodimunthiri, M. Rajarajan, and P. Tharmaraj, "Synthesis, characterization and biological activity of some new $\mathrm{VO}(\mathrm{IV}), \mathrm{Co}(\mathrm{II}), \mathrm{Ni}(\mathrm{II}), \mathrm{Cu}(\mathrm{II})$ and $\mathrm{Zn}(\mathrm{II})$ complexes of chromone based NNO Schiff base derived from 2-aminothiazole," Spectrochimica Acta A, vol. 82, no. 1, pp. 290-298, 2011.

[25] K. Z. Ismail, "Synthesis, spectroscopic, magnetic and biological activity studies of copper(II) complexes of an antipyrine Schiff base," Transition Metal Chemistry, vol. 25, no. 5, pp. 522-528, 2000.

[26] F. A. Cotton, G. Wilkinson, C. A. Murillo, and M. Bochmann, Advanced Inorganic Chemistry, Wiley, New York, NY, USA, 6th edition, 1999.

[27] M. M. Omar and G. G. Mohamed, "Potentiometric, spectroscopic and thermal studies on the metal chelates of 1-(2thiazolylazo)-2-naphthalenol," Spectrochimica Acta A, vol. 61, no. 5, pp. 929-936, 2005.

[28] K. Y. El-Baradie, "Preparation and characterization of sulfadiazine Schiff base complexes of $\mathrm{Co}(\mathrm{II}), \mathrm{Ni}(\mathrm{II}), \mathrm{Cu}(\mathrm{II})$, and Mn(II)," Monatshefte fur Chemie, vol. 136, no. 7, pp. 11391155, 2005.

[29] Y. S. Rao, B. Prathima, S. A. Reddy, K. Madhavi, and A. V. Reddy, "Complexes of $\mathrm{Cu}(\mathrm{II})$ and $\mathrm{Ni}(\mathrm{II})$ with bis(phenylthiosemicarbazone): synthesis, spectral, EPR and in vitro-antibacterial and antioxidant activity," Journal of the Chinese Chemical Society, vol. 57, no. 4, pp. 677-682, 2010.

[30] G. G. Mohamed and C. M. Sharaby, "Metal complexes of Schiff base derived from sulphametrole and o-vanilin. Synthesis, spectral, thermal characterization and biological activity," Spectrochimica Acta A, vol. 66, no. 4-5, pp. 949-958, 2007.

[31] C. M. Sharaby, "Preparation, characterization and biological activity of $\mathrm{Fe}(\mathrm{III}), \mathrm{Fe}(\mathrm{II}), \mathrm{Co}(\mathrm{II}), \mathrm{Ni}(\mathrm{II}), \mathrm{Cu}(\mathrm{II}), \mathrm{Zn}(\mathrm{II}), \mathrm{Cd}(\mathrm{II})$ and UO2(II) complexes of new cyclodiphosph(V)azane of sulfaguanidine," Spectrochimica Acta A, vol. 62, no. 1-3, pp. 326-334, 2005.

[32] M. Vaidyanathan, R. Viswanathan, M. Palaniandavar, T. Balasubramanian, P. Prabhaharan, and T. P. Muthiah, "Copper(II) complexes with unusual axial phenolate coordination as structural models for the active site in galactose oxidase: Xray crystal structures and spectral and redox properties of [Cu(bpnp)X] complexes," Inorganic Chemistry, vol. 37, no. 25, pp. 6418-6427, 1998.

[33] R. Karvembu and K. Natarajan, "Synthesis and spectral studies of binuclear ruthenium(II) carbonyl complexes containing bis( $\beta$-diketone) and their applications," Polyhedron, vol. 21, no. 2, pp. 219-223, 2002.

[34] P. S. Mane, S. G. Shirodkar, and T. K. Chondhekar, "Synthesis of complexes of copper(II), nickel(II), cobalt(II), 
manganese(II) and iron(III) with bidentate Schiff bases," Journal of the Indian Chemical Society, vol. 79, no. 4, pp. 376$378,2002$.

[35] J. Joseph and B. H. Mehta, "Synthesis, characterization, and thermal analysis of transition metal complexes of polydentate ONO donor Schiff base ligand," Russian Journal of Coordination Chemistry, vol. 33, no. 2, pp. 124-129, 2007.

[36] S. A. Sallam, A. S. Orabi, B. A. El-Shetary, and A. Lentz, "Copper, nickel and cobalt complexes of Schiff-bases derived from $\beta$-diketones," Transition Metal Chemistry, vol. 27, no. 4, pp. 447-453, 2002.

[37] P. Tharmaraj, D. Kodimunthiri, C. D. Sheela, and C. S. Shanmuga Priya, "Synthesis, spectral characterization, and antimicrobial activity of copper(II), cobalt(II), and nickel(II) complexes of 3-formylchromoniminopropylsilatrane," Journal of Coordination Chemistry, vol. 62, no. 13, pp. 2220-2228, 2009.

[38] R. Kannappan, R. Mahalakshmy, T. M. Rajendiran, R. Venkatesan, and P. Sambasiva Rao, "Magnetic, catalytic, EPR and electrochemical studies on binuclear copper(II) complexes derived from 3,4-disubstituted phenol," Proceedings of the Indian Academy of Sciences: Chemical Sciences, vol. 115, no. 1, pp. 1-14, 2003.

[39] D. Kivelson and R. Neman, "ESR studies on the bonding in copper complexes," The Journal of Chemical Physics, vol. 35, no. 1, pp. 149-155, 1961.

[40] R. K. Ray and G. B. Kauffman, "EPR Spectra and covalency of bis(amidinourea/O-alkyl-1-amidinourea)copper(II) complexes. Part II. Properties of the CuN42- chromophore," Inorganica Chimica Acta, vol. 173, no. 2, pp. 207-214, 1990.

[41] A. Majumder, G. M. Rosair, A. Mallick, N. Chattopadhyay, and S. Mitra, "Synthesis, structures and fluorescence of nickel, zinc and cadmium complexes with the N,N,O-tridentate Schiff base N-2-pyridylmethylidene-2-hydroxy-phenylamine," Polyhedron, vol. 25, no. 8, pp. 1753-1762, 2006.

[42] W. Wang, G. Springsteen, S. Gao, and B. Wang, "The first fluorescent sensor for boronic and boric acids with sensitivity at sub-micromolar concentrations," Chemical Communications, no. 14, pp. 1283-1284, 2000.

[43] N. Chattopadhyay, A. Mallick, and S. Sengupta, "Photophysical studies of 7-hydroxy-4-methyl-8- (4'-methylpiperazin$1^{\prime}$-yl) methylcoumarin: a new fluorescent chemosensor for zinc and nickel ions in water," Journal of Photochemistry and Photobiology A: Chemistry, vol. 177, no. 1, pp. 55-60, 2006.

[44] M. Jalali-Heravi, A. A. Khandar, and I. Sheikshoaie, "Theoretical investigation of the structure, electronic properties and second-order nonlinearity of some azo Schiff base ligands and their monoanions," Spectrochimica Acta A, vol. 55, no. 12, pp. 2537-2544, 1999.

[45] C. D. Sheela, C. Anitha, P. Tharmaraj, and D. Kodimunthri, "Synthesis, spectral characterization, and antimicrobial studies of metal complexes of the schiff base derived from [4amino-N-guanylbenzene sulfonamide] and salicylaldehyde," Journal of Coordination Chemistry, vol. 63, no. 5, pp. 884-893, 2010.

[46] M. Muthukumar and P. Viswanathamurthi, "Spectral, catalytic, and antifungal studies of ruthenium(II) chalcone complexes," Journal of Coordination Chemistry, vol. 63, no. 7, pp. 1263-1272, 2010.

[47] N. Raman, R. Jeyamurugan, and J. Joseph, "Anti-inflammatory and antimicrobial studies of biosensitive Knoevenagel condensate $\beta$-ketoanilide Schiff base and its $\mathrm{Co}(\mathrm{II}), \mathrm{Ni}(\mathrm{II})$,
$\mathrm{Cu}(\mathrm{II})$ and $\mathrm{Zn}$ (II) complexes," Journal of the Iranian Chemical Research, vol. 3, pp. 83-95, 2010.

[48] N. Raman and J. Joseph, "Synthesis, spectral characterization and antimicrobial activity of macrocyclic Schiff-base copper(II) complexes containing polycrystalline nanosized grains," Journal of Coordination Chemistry, vol. 62, no. 7, pp. 1162-1171, 2009. 


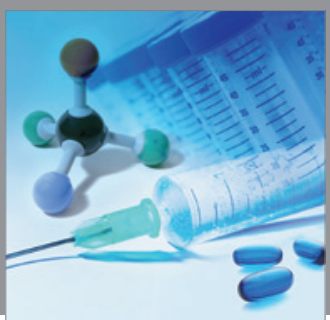

International Journal of

Medicinal Chemistry

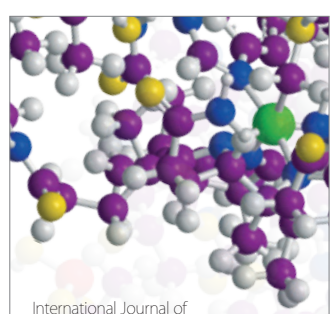

Carbohydrate Chemistry

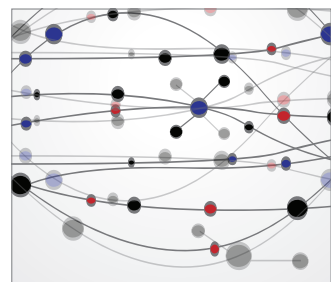

The Scientific World Journal
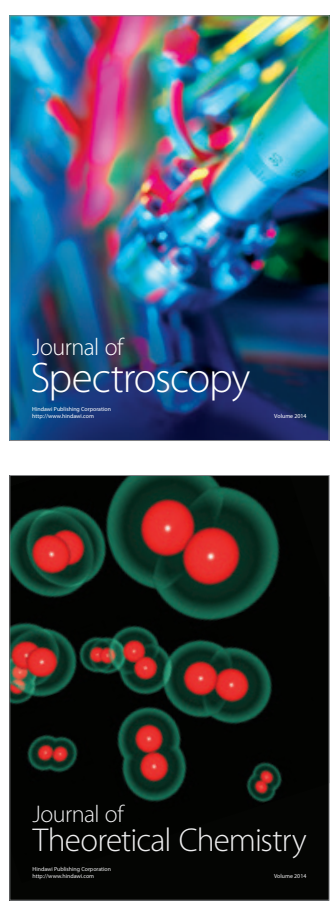
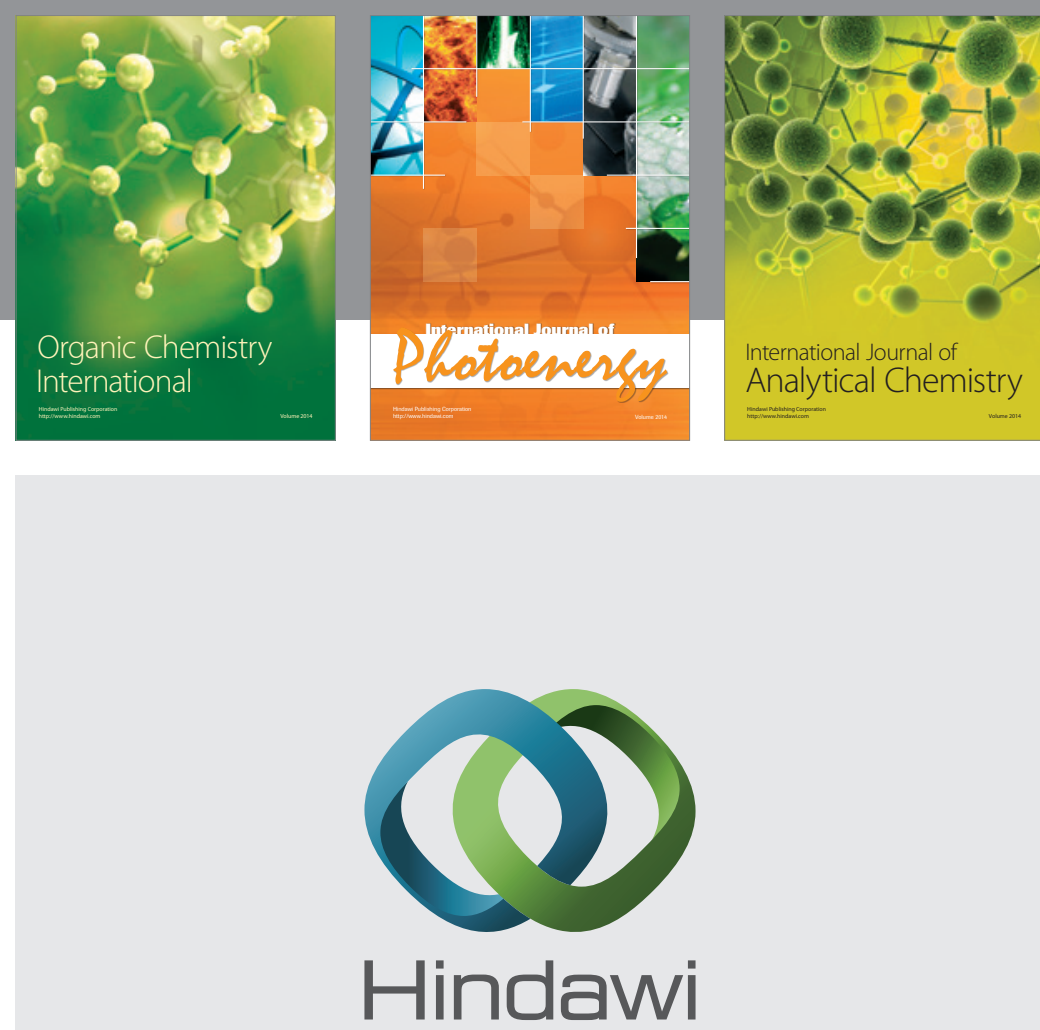

Submit your manuscripts at

http://www.hindawi.com
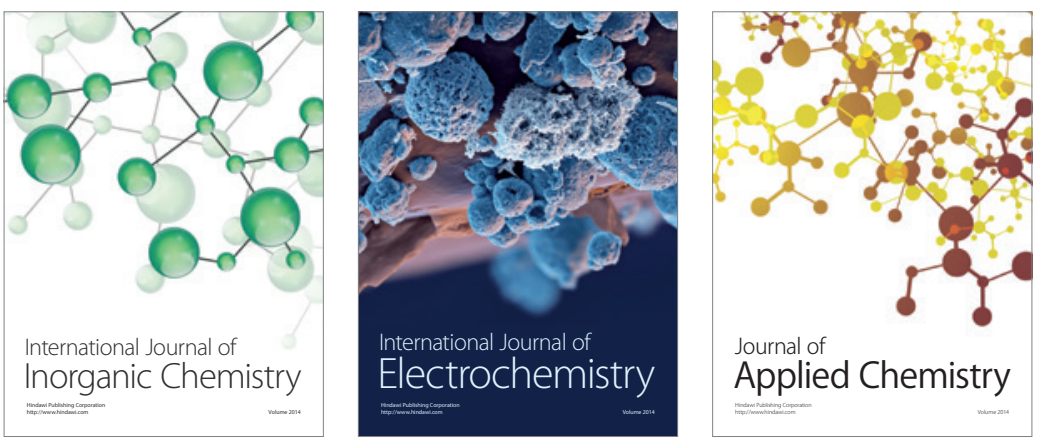

Journal of

Applied Chemistry
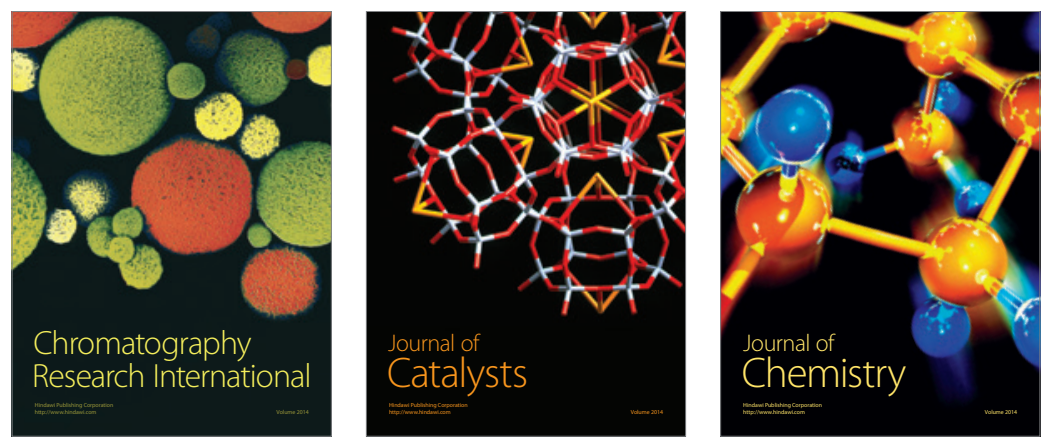
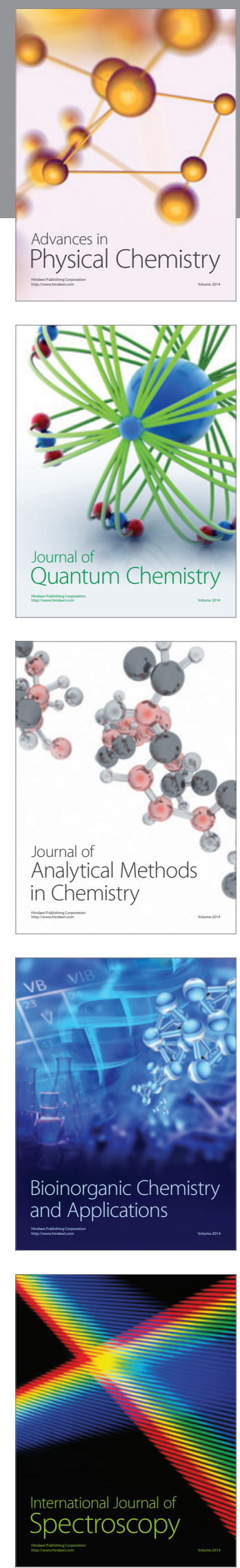